\title{
Experiment Research on Gasification Character of Pulverized Coal at Medium Temperature
}

\author{
Tong Lou ${ }^{1}$, Zhong-xiao Zhang ${ }^{1,2}$, Jun-jie Fan ${ }^{2}$, Hai-quan An ${ }^{2}$, Zhi-hao Zhou ${ }^{1}$, Pu-jie Yue ${ }^{1}$ \\ ${ }^{1}$ College of Environment and Architecture, University of Shanghai for Science and Technology, Shanghai, China \\ ${ }^{2}$ School of Mechanical Engineering, Shanghai Jiao Tong University, Shanghai, China \\ Email: zhzhx222@163.com
}

Received March, 2013

\begin{abstract}
In this paper, effect of gasification temperature and residence time on gasification characteristics of typical pulverized coals under atmosphere pressure were studied on a one-dimensional electric heating drop tube furnace system to evaluate gasification characteristics of pulverized coal at medium temperature. The results show that the gasification rate increases with the raising of the gasification temperature under the temperature among $1150^{\circ} \mathrm{C}$ and $1450^{\circ} \mathrm{C}$, and as the temperature is above $1350^{\circ} \mathrm{C}$, the increasing rate become slower. Cold gas efficiency and carbon conversion meet the maximum value when the temperature approaches the ash fusion point of coal. With the further rise of the temperature, ash on the surface of the char starts to be melted, the gasification reaction rate decreases, due to the hindrance of the effective contact between coal char and gasification agent. The gasification efficiency would become steady when the residence time exceeds $8 \mathrm{~s}$.
\end{abstract}

Keywords: Gasification Characteristic; Pulverized Coal; Carbon Conversion; Cold Gas Efficiency

\section{Introduction}

Issues on natural resource and environment become increasingly severely in China, due to the long-term use of traditional coal combustion. Integrated gasification combined cycle (IGCC) takes advantage on high efficient and environmentally-friendly, is a new power generation technology. Gasified is one of the key devices of IGCC power generation system. Compared to the other gasification technologies, entrained flow gasification technology get rapid development for its advantages of high gasification intensity, high carbon conversion and be easily practiced on a large scale. Influencing factors on gasification efficiency of entrained flow gasified are many, effect of gasification temperature and residence time on gasification characteristics of typical pulverized coals were studied on a one-dimensional electric heating drop tube furnace system under the conditions of atmosphere pressure and medium temperature from $1150^{\circ} \mathrm{C}$ to $1450^{\circ} \mathrm{C}[1-3]$.

\section{Experimental System and Work Conditions}

\subsection{Experimental System}

Figure 1 is the picture of experimental system, which is consisted of high temperature tube electric heating fur- nace, ash collected system and syngas cleaned and detected system. The furnace is made of corundum tube $(2.1$ $\mathrm{m}$ in length, $60 \mathrm{~mm}$ in inner diameter), the adjust temperature is up to $1550^{\circ} \mathrm{C}$, the gas analysis equipment is a infrared gas analyzer produced by Wuhan Cubic Optoelectronics Technology Co., Ltd., which can proceed real time measurement on $\mathrm{CO}, \mathrm{CO}_{2}, \mathrm{H}_{2}, \mathrm{CH}_{4}$ and $\mathrm{O}_{2}$.

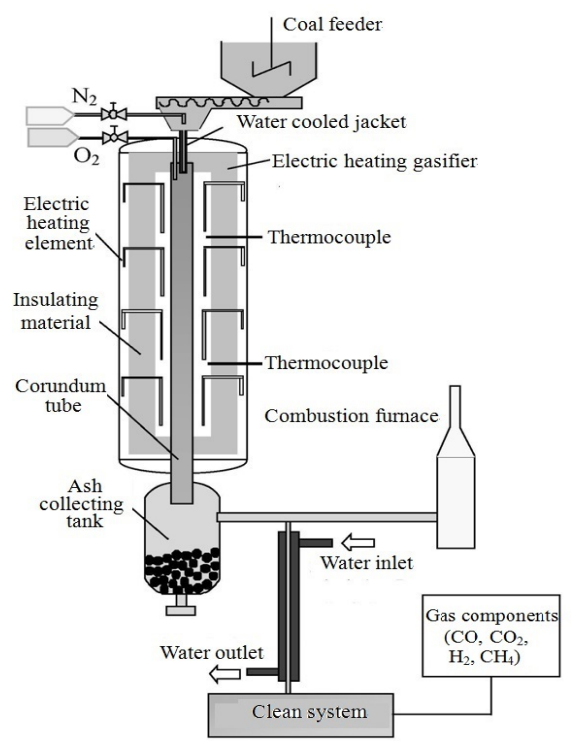

Figure 1. The schematic picture of the experimental process. 


\subsection{Work Conditions}

Datong bituminous coal, a typical bituminous coal in China was selected for the experiment on gasification characteristic of pulverized coal at medium temperature, and effect of gasification temperature and residence time were mainly considered. The average particle size of pulverized coal is more or less than $100 \mu \mathrm{m}$ (under 150 $\mu \mathrm{m})$ and the feeding rate is about $0.2 \mathrm{~kg} / \mathrm{h}$. The proximate analysis and the elemental analysis of the coal is in Table 1, the experimental operating conditions are in Table 2.

\subsection{Experimental Data Processing Methods}

It's relatively difficult to measure the syngas directly as its high temperature. So the total amount of dry gas could be obtained by the calculation of $\mathrm{N}_{2}$ balance, the divided relationship between the $\mathrm{N}_{2}$ amount in the inlet and the $\mathrm{N}_{2}$ percentage of dry gas in the outlet: $Q=\frac{Q_{i n, N_{2}}}{\alpha_{N_{2}}}$, thereinto, $\mathrm{Q}$ is the flow of syngas, $Q_{i n, N_{2}}$ is the flow of $\mathrm{N}_{2}$ amount in the inlet, $\alpha_{N_{2}}$ is the gas volume fraction of $\mathrm{N}_{2}$ in the dry gas.

As the experiment proceeded in one-dimensional drop tube furnace, residence time of pulverized coal staying in the furnace is equal to the residence time of reactivity gas:

Table 1. Proximate analysis and the elemental analysis of the datong coal.

\begin{tabular}{ccc}
\hline Coal & & Datong \\
\hline & Mad & 1.61 \\
Proximate analysis $(\%)$ & Aad & 26.89 \\
& Vad & 28.26 \\
& FCad & 42.34 \\
& Cad & 77.78 \\
Ultimate analysis $(\%)$ & Had & 5.39 \\
& Oad & 12.79 \\
& Nad & 1.09 \\
& Sad & 2.69 \\
Ash fusion temperature $\left({ }^{\circ} \mathrm{C}\right)$ & DT & 1350 \\
& ST & 1370 \\
& FT & 1400 \\
\hline
\end{tabular}

Table 2. The Experimental operating conditions.

\begin{tabular}{cccc}
\hline Pressure & $\begin{array}{c}\text { Temperature } \\
\left({ }^{\circ} \mathrm{C}\right)\end{array}$ & $\begin{array}{c}\text { Residence time } \\
(\mathrm{S})\end{array}$ & $\begin{array}{c}\text { Ratio of } \\
\mathrm{O} / \mathrm{C}\end{array}$ \\
& & 10 & \\
\multirow{4}{*}{ 1atm } & 1150 & 8 & \\
& 1250 & 6 & $1: 1$ \\
& 1350 & 4 & \\
\hline
\end{tabular}

$$
t=\frac{2881 \pi r^{2}}{(273+T)\left(Q_{i n, N_{2}}+Q_{i n, O_{2}}\right)},
$$

thereinto, $\mathrm{L}$ is the length of the furnace, $\mathrm{r}$ is the inner diameter of the furnace, $T$ is the temperature of the furnace; and $Q_{i n, O_{2}}$ is the flow of $\mathrm{O}_{2}$ in the inlet.

Oxygen element of the gas products is mainly from pulverized coal and the injected $\mathrm{O}_{2}$ in the inlet, such as $\mathrm{CO}, \mathrm{CO}_{2}$ and $\mathrm{H}_{2} \mathrm{O}$. Therefore, the amount of vapor in the syngas can be calculated by the balance of $\mathrm{O}_{2}$ element, the amount of vapor in the syngas $(\mathrm{mol})=$ oxygen amount of the injected $\mathrm{O}_{2}+$ oxygen amount of coal - the amount of the oxygen element from carbon dioxide and carbon monoxide in the gas, the calculation formula is

$$
\begin{aligned}
\alpha_{\mathrm{H}_{2} \mathrm{O}}= & \frac{2 Q_{i n, \mathrm{O}_{2}} / 22.4+M \gamma_{\mathrm{C}} / 16-2 Q \alpha_{\mathrm{CO}_{2}} / 22.4-Q \alpha_{\mathrm{CO}} / 22.4}{Q+2 Q_{i n, \mathrm{O}_{2}} / 22.4+M \gamma_{\mathrm{C}} / 16-2 Q \alpha_{\mathrm{CO}_{2}} / 22.4-Q \alpha_{\mathrm{CO}} / 22.4} \\
& \times 100 \%
\end{aligned}
$$

Thereinto, $\alpha$ is the gas volume fraction of in the dry gas.

Carbon conversion $\eta$ is the index to calculate how much carbon is transferred to the content in gas during the gasification process:

$$
\eta=\frac{\left(V_{\mathrm{CO} 2}+V_{C O}+V_{\mathrm{CH}_{4}}\right) / 22.4}{M \gamma_{C} / 12} \times 100 \%,
$$

thereinto, $\mathrm{V}$ is gas volume, $\mathrm{M}$ is the amount of coal; and $\gamma_{C}$ is the amount of carbon in the coal.

Cold gas efficiency $\eta_{d}$ is the heat value proportion of fuel and gas products, the calculation formula are:

$$
\eta_{d}=\frac{h_{\mathrm{H}_{2}}+h_{\mathrm{CO}}+h_{\mathrm{CH}_{4}}}{h_{f, \text { coal }}} \times 100 \%,
$$

thereinto, $\mathrm{h}$ is the gas heat value, $h_{f, \text { coal }}$ is the heat value of coal.

\section{Experimental Results and Discussions}

In an actually running entrained flow gasified, the controllable parameter is the feeding rate of coal and $\mathrm{O}_{2}$, residence time and the amount of steam. Commonly, gasification temperature and the atmosphere inside the furnace can be adjusted by changing the rate of $\mathrm{O} / \mathrm{C}$. This adjustment would change the processes of gasification reactivity and the content of syngas, which would definitely change the residence time of gasification agent in the furnace. Therefore, research of gasification temperature and residence time on the gasification characteristic of coal has a significant meaning for the design and following operation of the gasified [4].

\subsection{Effect of Temperature and Residence Time on the Composition of Syngas}

The method of changing injecting rate of $\mathrm{N}_{2}$ to change 
the residence time of pulverized coal staying in the furnace was selected in this paper, the range is from $3 \mathrm{~s}$ to 10s. Figure 2 shows the effect of gasification temperature and residence time on the composition of syngas [5].

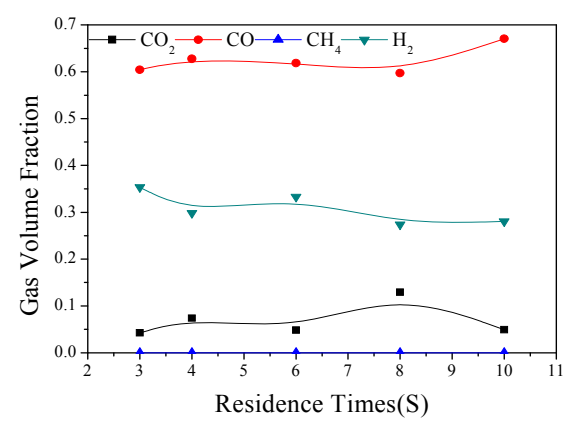

(a) Temperature: $1450^{\circ} \mathrm{C}$

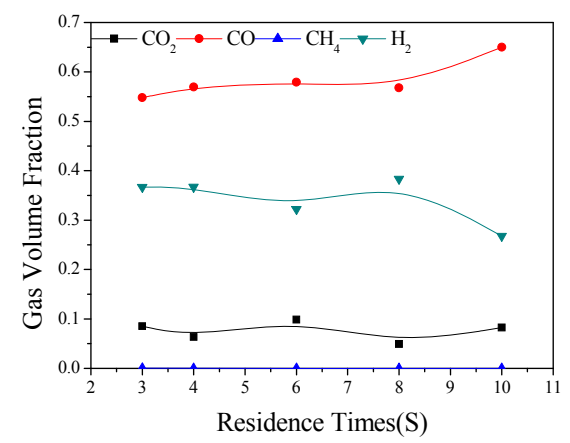

(b) Temperature: $1350^{\circ} \mathrm{C}$

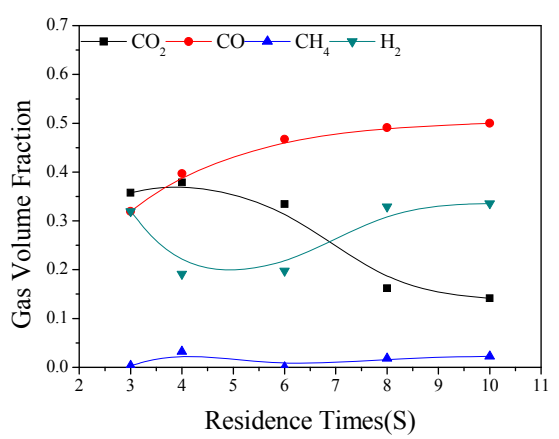

(c) Temperature: $1250^{\circ} \mathrm{C}$

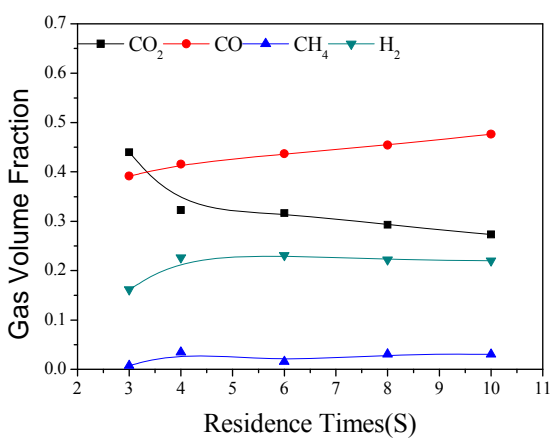

(d) Temperature: $1150^{\circ} \mathrm{C}$

Figure 2.The effect of temperature and residence time on the components of synthesis gas of Datong Coal
As the figure shows that the composition of the syngas changes with residence time under different gasification temperature conditions, the content of $\mathrm{CO}$ increases with the increasing of residence time. When the temperature is higher than $1300^{\circ} \mathrm{C}$, the increasing rate becomes smaller and the content of $\mathrm{H}_{2}$ slightly decreases with the increasing of the residence time, while the content of $\mathrm{CO}_{2}$ generally remains steady. When the gasification temperature is lower than $1300^{\circ} \mathrm{C}$, the increasing rate of $\mathrm{CO}$ is relatively bigger, and the fluctuation of $\mathrm{H}_{2}$ and $\mathrm{CO}_{2}$ is quite drastic as well. The content of $\mathrm{CO}_{2}$ falls down with the increase of residence time. With the increase of residence time, the content of $\mathrm{H}_{2}$ would increase first and then decrease while the temperature is $1250^{\circ} \mathrm{C}$. This is mainly caused by the reactivity of $\mathrm{H}_{2} \mathrm{O}-\mathrm{C}$ is higher than $\mathrm{CO}_{2}-\mathrm{C}$. As the residence time decreases to a certain extent, combustion reactions are mainly happened in the furnace and most of coal char would escape from the furnace directly without reacting with $\mathrm{H}_{2} \mathrm{O}$ and $\mathrm{CO}_{2}$. So, most of $\mathrm{H}_{2}$ are mainly produced by the paralysis of coal at this condition. With the increase of residence time, the reacting time between $\mathrm{H}_{2} \mathrm{O}-\mathrm{C}$ and $\mathrm{CO}_{2}-\mathrm{C}$ would be extended correspondingly. Followed by the large products of $\mathrm{CO}_{2}$ and $\mathrm{CO}$, the volume proportion of $\mathrm{H}_{2}$ in the syngas would be decreased. Due to the reactivity of $\mathrm{H}_{2} \mathrm{O}-\mathrm{C}$ is bigger than $\mathrm{CO}_{2}-\mathrm{C}$, the volume proportion of $\mathrm{H}_{2}$ in the syngas increases again with the further increasing of residence time. It can also be seen from the Figure that the volume proportion of $\mathrm{CH}_{4}$ gets down gradually with the rise of the temperature. When the temperature is above than $1350^{\circ} \mathrm{C}$, the volume proportion of $\mathrm{CH}_{4}$ drops to 0 , which indicates that $\mathrm{CH}_{4}$ is mainly from the volatile components, and the higher temperature of gasification reaction is, the easier $\mathrm{CH}_{4}$ be decomposed [6,7].

\subsection{The Effect of Temperature and Residence Time on the Carbon Conversion and Cold Gas Efficiency}

Figure 3 shows the effect of temperature and residence time on carbon conversion and cold gas efficiency of Datong coal. It can be seen from Figure that the carbon conversion and cold gas efficiency increases with the increase of residence time. When it is lower than $1350^{\circ} \mathrm{C}$, carbon conversion and cold gas efficiency increases with the increasing of gasification temperature. When it is higher than $1450^{\circ} \mathrm{C}$, carbon conversion and cold gas efficiency almost remains the same as that at $1350^{\circ} \mathrm{C}$, even slightly lower. The main reason is that the ash would be appeared and accumulated on the surface of coal char particles with the proceeding of gasification reactions, when the gasification temperature is higher than the ash fusion temperature, it would be transferred to liquid phase. It tends to shrink as globular material on the surface 

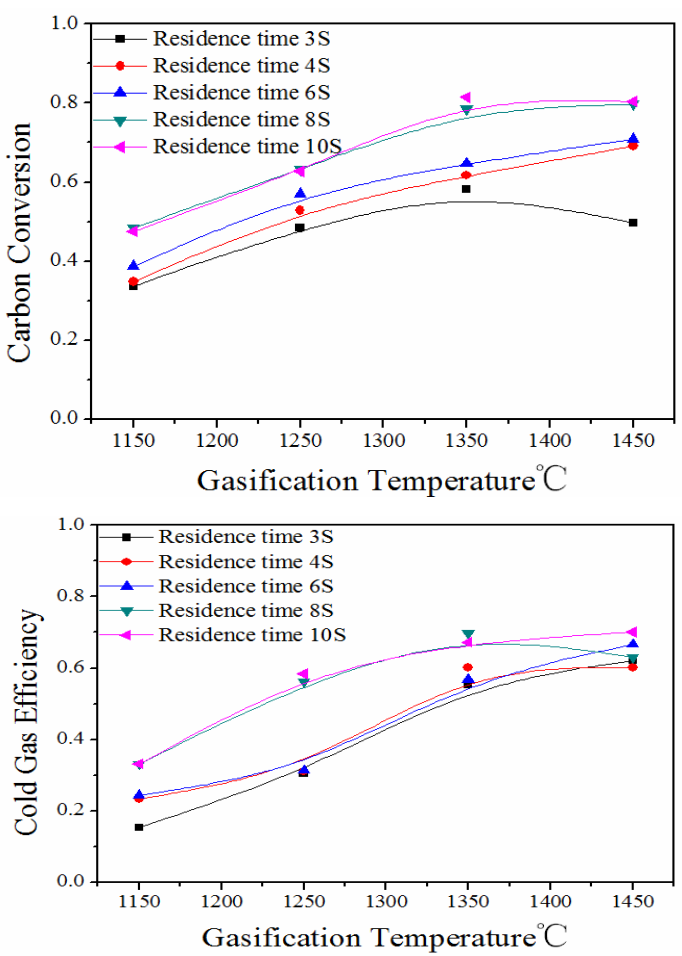

Figure 3. Effect of Temperature and Residence Time on the Carbon Conversion and Cold Gas Efficiency of Datong Coal.

lead to the decrease of effective surface area or separated the char particles from the reacting gases by wrapped the char particles. So the gasification reactivity and gasification reaction rate would be greatly reduced, caused carbon conversion and cold gas efficiency decrease at temperature higher than the ash fusion temperature, which is consistent with the research result of $\mathrm{Lu}$ Cheng, Jae Goo Lee and so on [8-11].

\section{Conclusions}

1) The temperature is one of the most important factors affecting the gasification characteristic of pulverized coal. Under the experimental condition of temperature from $1150^{\circ} \mathrm{C}$ to $1450^{\circ} \mathrm{C}$, the higher the gasification temperature is, the faster gasification rate of pulverized coal is, and when the temperature is higher than $1350^{\circ} \mathrm{C}$, the increasing rate becomes slow down. The maximum carbon conversion is more or less than $80 \%$ under experimental conditions.

2) The residence time also has a great influence on gasification of pulverized coal. The carbon conversion and cold gas efficiency goes up with the increase of the residence time under the same temperature conditions. And carbon conversion and cold gas efficiency remains steady after 8 seconds.

3) When the temperature approaches to the coal ash fusion temperature, the carbon conversion and cold gas efficiency reaches the maximum value. With the further increase of temperature, the ash content on the surface of char begins to fuse, which would hinder the effective contact between char and gasification agent and lead to a decline for the gasification reaction rate.

\section{REFERENCES}

[1] X. J. Wu, Z. X. Zhang, X. Y. Xu et al., "Experimental Study on Gasification and Ash Fusion Characteristics of Coal with High Ash Fusion Temperatures," Journal of Chinese Society of Power Engineering, Vol. 31, No. 7, 2011, pp. 557-562.

[2] X. J. Wu, Z. X. Zhang, G. L. Piao et al., "Gasification Characteristics of Coal with High Ash Fusion Temperature in Lab-Scale Down-Flow Gasifier," Journal of Combustion Science and Technology, Vol. 15, No. 2, 2009, pp. 182-186.

[3] Y. S. Shin, S. M. Choi and D. H. Ahn, "Pressurized Drop tube Furnace Tests of Global Coal Gasification Characteristics," Energy Research, Vol. 24, 2000, pp. 749-758. doi:10.1002/1099-114X(200007)24:9<749::AID-ER614> 3.0.CO;2-I

[4] X. J. Wu, Z. X. Zhang, G. L. Piao et al., "Experimental Study on Gasification Characteristics of Coal in Lab-scale Down Flow Gasifier," Journal of Engineering Thermophysics, Vol. 29, No. 8, 2008, pp. 1431-1434.

[5] X. J. Wu. Experimental Study And Numerical Simulation of Pressured High Temperature Entrained Flow Coal Gasification With High Ash Fusion TmeperatureCoal," PHD thesis of University of Shanghai for Science and Technology, 2007.

[6] G. Y. Chen, Z. X. Zhang, B. Q. Dai, et al., "Experiment Study on Solid Slag in an Entrained Flow Coal Gasifier," Proceeding of the CSEE, 2009. Vol. 29, No. 23, pp. 73-79.

[7] G. Y. Chen, "Study and Numerical Simulation of Gasification Mechanism and Ash Characteristic in An Entrained Flow Pulverized Coal Gasification," PHD thesis of University of Shanghai for Science and Technology, 2010.1

[8] C. Lu, Z. X. Zhang, X. J. Wu, et al., "Experimental Study on Effects of Operation Parameters on Entrained Flow Pulverized Coal Gasification," Clean Coal Technology, Vol. 16, No. 2, 2010, pp. 49-53.

[9] J. G. Lee, J. H. Kim, H. J. Lee, T. J. Park and S. D. Kim, "Characteristics of Entrained Flow Coal Gasification in a Drop Tube Reactor," Fuel, Vol. 75, No. 9,1996, pp. 1035-1042. doi:10.1016/0016-2361(96)00084-1

[10] Y. J. Kim, J. M. Lee and S. D. Kim, "Modeling of Coal Gasification in an Internally Circulating Fluidized Bed Reactor with Draught Tube," Fuel, Vol. 79, 2000, pp. 69-77.doi:10.1016/S0016-2361(99)00128-3

[11] Y. J. Kim, S. H. Lee and S. D. Kim, "Coal gasification characteristics in a Downer Reactor," Fuel, No. 80, 2011, pp.1915-1922.doi:10.1016/S0016-2361(01)00052-7 